\title{
EFICIÊNCIA DA Azospirillum brasilense COMBINADA COM DOSES DE NITROGÊNIO NO DESENVOLVIMENTO DE PLANTAS DE MILHO
}

\author{
RODRIGO ALBERTO REPKE ${ }^{1}$, SIHÉLIO JÚLIO SILVA CRUZ ${ }^{1}$, \\ CARLOS JORGE DA SILVA ${ }^{1}$, PRISCILA GONZALES FIGUEIREDO ${ }^{1}$ e SILVIO JOSÉ BICUDO ${ }^{1}$
}

${ }^{1}$ Unesp, Botucatu, SP, Brasil, rodrigorepke@hotmail.com, sihelio@agronomo.eng.br, carloscjs82@gmail.com, sjbicudo@fca.unesp.br

$\overline{\text { Revista Brasileira de Milho e Sorgo, v.12, n.3, p. 214-226, } 2013}$

\begin{abstract}
RESUMO - Este trabalho teve como objetivo avaliar o efeito do uso da bactéria diazotrofica Azospirillum brasilense inoculada via sementes em associação com doses de nitrogênio no desenvolvimento de plantas de milho. A pesquisa foi composta por um ensaio com delineamento experimental de blocos ao acaso, com quatro repetições, em esquema fatorial duplo. O fator 1, dois níveis: sem e com aplicação da solução da bactéria Azospirillum brasilense nas sementes; e o fator 2, seis doses totais de nitrogênio: zero, 80,105, 130, 155 e $180 \mathrm{~kg} \mathrm{ha}^{-1}$. As avaliações morfológicas da planta e da espiga foram realizadas aos 20,40, 60, 80 e 100 dias após a emergência. A aplicação da bactéria diazotrofica Azospirillum brasilense via solução nas sementes, acompanhada ou não de doses de nitrogênio sintético, não interfere no desenvolvimento de plantas e na produtividade da cultura do milho. A adoção desta prática não substitui o uso de fertilizantes nitrogenados e tampouco permite a redução da dose. A adição de fertilizantes nitrogenados promove maior desenvolvimento das plantas, com aumento da produtividade.
\end{abstract}

Palavras-chave: Zea mays; fixação biológica de nitrogênio; adubação nitrogenada.

\section{Azospirillum brasilense EFFICIENCY IN COMBINATION WITH DOSES OF NITROGEN IN THE DEVELOPMENT OF MAIZE}

\begin{abstract}
This study aimed to evaluate the effect of the use of diazotrophic bacterium Azospirillum brasilense inoculated to seeds in combination with nitrogen on the development of corn plants. The experiment was carried out in field using a randomized block design in a double factorial arrangement with four reapplications.. The factor 1: with and without the bacterium application in the seed; and factor 2: six nitrogen doses: 0, 80, 105, 130, 155 and $180 \mathrm{~kg} \mathrm{ha}^{-1}$. The trangenic maize hybrid 2B587 Hx was used. The morphological evaluations of plant and ear were done at 20, 40, 60, 80 and 100 days after emergence (DAE). Grain yield was measured at 115 DAE. The application of diazotrophic bacterium Azospirillum brasilense solution via the seeds, with or without synthetic nitrogen did not interfere with plant development and yield of maize. The adoption of this practice does not replace the use of nitrogen fertilizers nor allows dose reduction. The addition of nitrogen fertilizers promotes greater plant growth and increased productivity.
\end{abstract}

Key words: Zea mays; biological nitrogen fixation; nitrogen fertilization. 
O milho (Zea mays L.) é uma cultura mundialmente importante em virtude de sua diversidade de utilização, da extensão da área cultivada e de sua elevada capacidade produtiva. Os maiores produtores mundiais são os Estados Unidos, a China e o Brasil. Porém, o manejo inadequado da adubação ainda é um dos principais fatores que contribuem para que não ocorra aumento da produtividade (USDA, 2011).

É uma cultura exigente em nutrientes, principalmente o nitrogênio $(\mathrm{N})$, cuja deficiência pode reduzir entre $10 \%$ e $22 \%$ o rendimento de grão. As plantas deficientes em $\mathrm{N}$ apresentam amarelecimento das folhas mais velhas, seguidas de clorose generalizada e perda foliar. Em alguns casos, podem ser observadas deformações nas pontas das espigas (Subedi et al., 2009).

A maioria dos solos das regiões tropicais é deficiente em $\mathrm{N}$ e, geralmente, apenas $50 \%$ do $\mathrm{N}$-fertilizante aplicado nesses solos é aproveitado pelas plantas, sendo o restante perdido por lixiviação e volatilização, entre outras causas. $\mathrm{O}$ aumento da demanda por fertilizantes nitrogenados, aliado ao seu elevado custo, tem direcionado as pesquisas para o processo de fixação natural (Saikia \& Jain, 2007).

$\mathrm{Na}$ natureza, alguns organismos procariotos conseguem assimilar o $\mathrm{N}$ atmosférico e transformá-lo em NH3, processo chamado de fixação biológica, realizado através do complexo enzimático nitrogenase. A fixação biológica pode ser responsável por aproximadamente $65 \%$ do total de $\mathrm{N}$ fixado na Terra, sendo, assim, o segundo processo biológico mais importante depois da fotossíntese (Cantarella, 2007).

Nas raízes de muitas plantas cultivadas, existem populações ativas de microorganismos diazotróficos, fixadores de $\mathrm{N}$, em associações que, com o passar do tempo, sofreram especificações, produzindo relações muito estreitas entre a planta e a bactéria. Dentre os microorganismos fixadores de $\mathrm{N}$ encontrados em associações com raízes de gramíneas, as espécies do gênero Azospirillum constituem um dos grupos mais estudados (Hartmann \& Baldam, 2006).

Esses microorganismos pertencem à subclasse $\alpha$ das proteobactérias, a qual comporta um grande número de bactérias simbióticas e associativas a plantas, tais como Rhizobium, Bradyrhizobium, Agrobactetirium e Gluconacetobacter. Essas bactérias são gram-negativas de vida livre, com metabolismo de carbono e $\mathrm{N}$ bastante versáteis, conferindo-lhes competitividade durante o processo de colonização. Utilizam no seu metabolismo fontes de $\mathrm{N}$ como amônia, nitrato, nitrito, aminoácidos e nitrogênio molecular. A forma de ação de bactárias Azospirillum ainda não foi totalmente compreendida. Até o momento, sabe-se que possuem capacidade de fixar $\mathrm{N}$ atmosférico quando associadas com gramíneas, podendo atuar na solubilização do fosfato inorgânico. O Azospirillum spp. apresenta ampla distribuição nos solos tropicais e subtropicais (Elmerich \& Newton, 2007).

A principal barreira à utilização do Azospirillum na cultura do milho tem sido a inconsistência dos resultados de pesquisa, que podem variar de acordo com a cultivar, as condições edafoclimáticas e a metodologia de condução da pesquisa (Bartchechen et al., 2010).

Assim, objetivou-se avaliar o efeito do uso da bactéria diazotrófica Azospirillum brasilense inoculada via sementes em associação com doses de nitrogênio no desenvolvimento de plantas de milho. 


\section{Material e Métodos}

O estudo foi realizado no ano agrícola 2010/2011, na Faculdade de Ciências Agronômicas da Universidade Estadual Paulista "Júlio de Mesquita Filho", município de Botucatu, SP. A localização geográfica da área experimental está definida pelas seguintes coordenadas: latitude $22^{\circ} 51^{\prime}$ $\mathrm{S}$, longitude $48^{\circ} 26^{\prime} \mathrm{W}$ Grw e altitude de $786 \mathrm{~m}$. O clima de Botucatu, SP, segundo a classificação de Köppen, é do tipo $\mathrm{Cwb}$, que significa clima mesotérmico com inverno seco.

O delineamento experimental adotado foi o de blocos ao acaso, com quatro repetições, em esquema fatorial duplo. $\mathrm{O}$ fator 1 teve dois tratamentos, sem e com aplicação da solução da bactéria
Azospirillum brasilense nas sementes, e o fator 2, seis níveis, correspondentes a doses totais de nitrogênio de zero, $80,105,130,155,180 \mathrm{~kg} \mathrm{ha}^{-1}$ (Tabela 1).

Foi utilizado o híbrido transgênico 2B587 Hx, que possui ciclo precoce, porte baixo e é indicado para semeadura no verão. Além disso, apresenta bom empalhamento, grãos de coloração amarelo-alaranjada e textura semidentada.

A parcela experimental correspondeu a 25,5 $\mathrm{m}^{2}$, sendo seis linhas de $5 \mathrm{~m}$, espaçadas a $0,85 \mathrm{~m}$, objetivando densidade de 58.824 plantas por hectare. Os dados obtidos foram submetidos à análise de variância e as médias comparadas através do teste T. Realizou-se também a análise de regressão polinomial em função das doses de $\mathrm{N}$ nos tratamentos

TABELA 1. Tratamentos aplicados na implantação e nos estádios fenológicos quatro e seis folhas totalmente estendidas V4 e V6, respectivamente, em ensaio de campo com híbrido de milho 2B587Hx.

\begin{tabular}{cccccc}
\hline & \multirow{2}{*}{$\begin{array}{c}\text { Solução de } \\
\text { Trat. }\end{array}$} & $\begin{array}{c}\text { Azospirillum } \\
\text { brasilense }\end{array}$ & Total & Implantação & Coses de Nitrogênio kg ha ${ }^{-1}$ \\
\cline { 3 - 6 } & Sem & Zero & Zero & Zero & Zero \\
\hline 1 & Com & Zero & Zero & Zero & Zero \\
2 & Sem & 180 & 30 & 80 & 70 \\
3 & Com & 180 & 30 & 80 & 70 \\
4 & Sem & 155 & 30 & 80 & 45 \\
5 & Com & 155 & 30 & 80 & 45 \\
6 & Sem & 130 & 30 & 80 & 20 \\
7 & Com & 130 & 30 & 80 & 20 \\
8 & Sem & 105 & 30 & 75 & Zero \\
9 & Com & 105 & 30 & 75 & Zero \\
10 & Sem & 80 & 30 & 50 & Zero \\
11 & Com & 80 & 30 & 50 & Zero \\
\hline
\end{tabular}

"Número de bactérias por $\mathrm{ml}=2.10^{8}$ 
com e sem aplicação de Azospirillum brasilense. Os parâmetros morfológicos da planta, os componentes da espiga e a produtividade foram avaliados através da correlação simples de Pearson.

Os dados climatológicos relativos ao período experimental de dezembro de 2010 a abril de 2011, período no qual se deu o desenvolvimento da cultura do milho, estão apresentados na Figura 1.

O solo da área experimental foi classificado como Latossolo Vermelho distroférrico de textura argilosa (Embrapa, 1999), com relevo suave ondulado e com boa drenagem. A área foi anteriormente cultivada com milho no verão e aveia preta no inverno. O preparo do solo foi realizado através de aração e gradagem, grade aradora com 10 discos de 26 polegadas e grade niveladora com 32 discos de 18 polegadas, e a caracterização química do solo, feita de acordo com as metodologias de Raij et al. (2001), é disposta na Tabela 2.

No tratamento das sementes com a solução de bactérias fixadores de nitrogênio, foi aplicada a dose recomendada pelo fabricante, equivalente a $100 \mathrm{ml}$ do inoculante comercial ha- ${ }^{-1}$ do produto Masterfix Gramíneas Líquido, na concentração de 2.108 bactérias $\mathrm{ml}^{-1}$. Minutos antes da semeadura, foram aplicados 3,06 $\mathrm{ml}$ do produto comercial em 1.800 sementes, resultando na média de $340 \mathrm{mil}$ unidades formadoras de colônia por semente. Para tanto, foram utilizados sacos de plástico onde as sementes, previamente contadas, receberam o produto. Para homogeneização da distribuição da solução, as embalagens foram agitadas por 5 min após a aplicação do produto. As sementes inoculadas não foram tratadas com fungicidas e inseticidas.

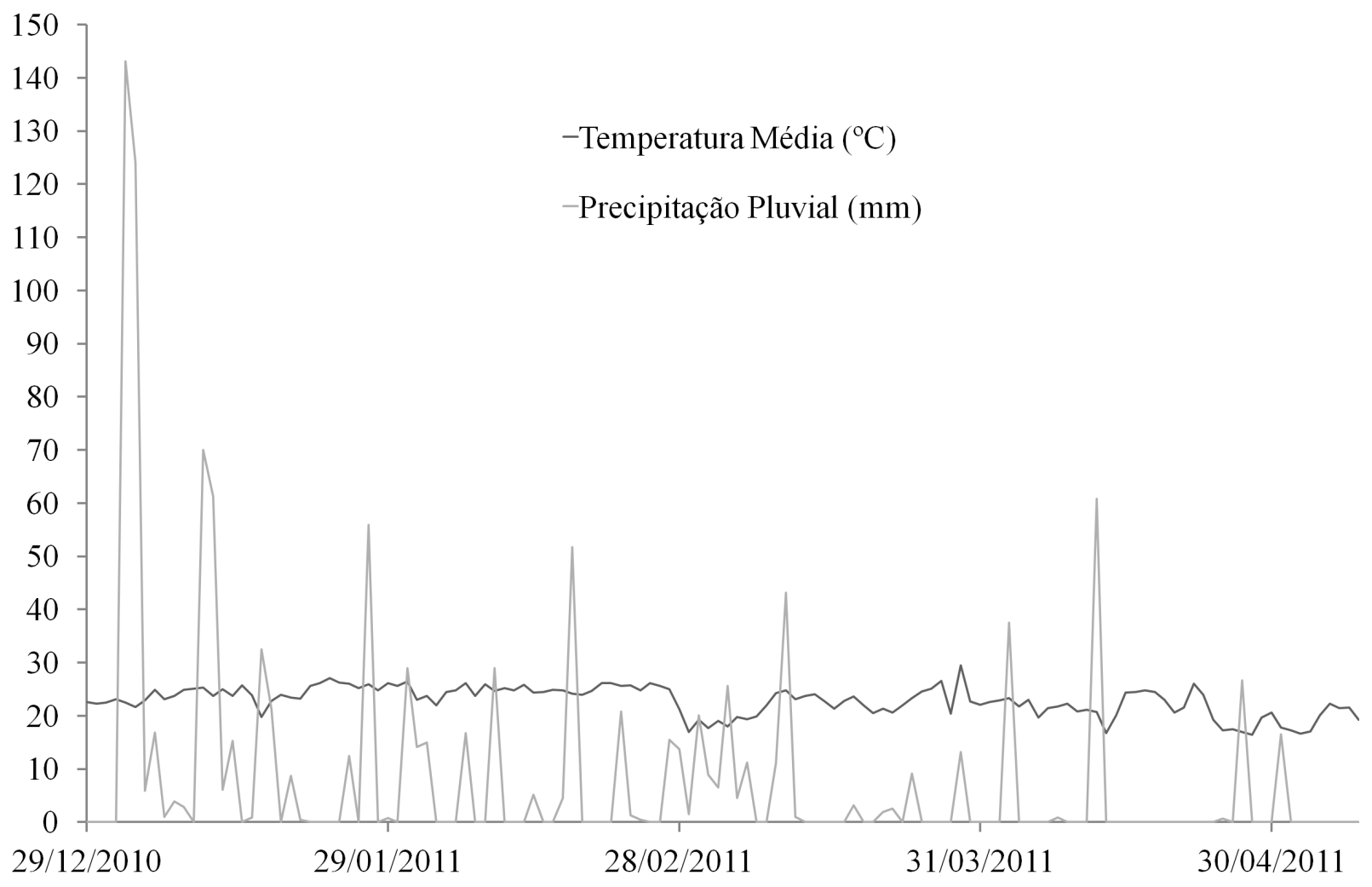

FIGURA 1. Dados climatológicos do período de dezembro de 2010 a abril de 2011. 
TABELA 2. Resultados da análise química do solo da área experimental nas camadas de 0-20 e 20-40 cm de profundidade, amostrados antes da instalação do experimento.

\begin{tabular}{|c|c|c|c|c|c|c|c|c|c|c|c|c|}
\hline \multirow{2}{*}{$\begin{array}{l}\text { Profundidade } \\
\qquad(\mathrm{cm})\end{array}$} & \multirow{2}{*}{$\mathrm{pH} \mathrm{CaCl}{ }_{2}$} & M.O & P resina & $\mathrm{Al}^{3+}$ & $\mathrm{H}+\mathrm{Al}$ & $\mathrm{K}$ & $\mathrm{Ca}$ & $\mathrm{Mg}$ & SB & CTC & $\mathrm{S}$ & \multirow{2}{*}{ V\% } \\
\hline & & $\mathrm{g} \mathrm{dm}^{3}$ & ---- & ----- & --- & --- & $\mathrm{dm}$ & 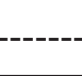 & & 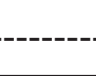 & ---- & \\
\hline $0-20$ & 5,1 & 43 & 31 & 2 & 31 & 4,7 & 46 & 20 & 71 & 101 & 17 & 70 \\
\hline $20-40$ & 5,1 & 36 & 16 & 2 & 34 & 2,8 & 41 & 19 & 63 & 97 & 17 & 65 \\
\hline
\end{tabular}

A semeadura foi realizada manualmente no dia 20 de dezembro de 2010. Foram dispostas na linha de semeadura duas sementes a cada $0,20 \mathrm{~m}$, em profundidade média de 0,04 $\mathrm{m}$ em linhas espaçadas $0,85 \mathrm{~m}$ entre si. Cinco dias após a emergência das plântulas, foi realizado o desbaste, deixando apenas uma planta a cada $0,20 \mathrm{~m}$, objetivando densidade de 58.824 plantas por hectare.

A adubação de implantação consistiu na aplicação de fertilizante formulado N-P-K na concentração 0-20-20, sendo as fontes de $\mathrm{P}_{2} \mathrm{O}_{5}$ e $\mathrm{K}_{2} \mathrm{O}$ superfosfato triplo e cloreto de potássio, respectivamente. Foram aplicados $300 \mathrm{~kg} \mathrm{ha}^{-1}$ do formulado no fundo do sulco de semeadura, objetivando a obtenção de produtividades entre 8 a $10 \mathrm{t}$ de grãos ha ${ }^{-1}$ (Raij et al., 2001). Os tratamentos constituídos com doses de nitrogênio receberam na adubação de semeadura $30 \mathrm{~kg} \mathrm{~N} \mathrm{ha}^{-1}$, via pulverização de calda na parede do sulco de semeadura. A fonte de fertilizante nitrogenado para a composição da calda foi ureia $(45 \%$ de N). Na aplicação das doses de N, foi utilizado um pulverizador costal de pressão constante com barras de 2 bicos (Bicos $=$ S.S. CO. FULLJET FL-8VC), espaçados a 0,85 m, com pressão de 3,1 $\mathrm{kgf} \mathrm{\textrm {cm } ^ { - 2 }}$ e velocidade de aplicação de $1 \mathrm{~m} \mathrm{~s}^{-1}$. A parcela experimental correspondeu a seis linhas de 5 $\mathrm{m}$, espaçadas a $0,85 \mathrm{~m}\left(25,5 \mathrm{~m}^{2}\right)$, onde foi aplicado
1,35 1 da solução ureia + água, correspondendo a um volume de calda de 533,3 1 ha $^{-1}$. A aplicação de nitrogênio foi realizada na parede do sulco aberto para semeadura. A adubação de cobertura foi realizada quando as plantas atingiram os estádios fenológicos V4 e V6, como descrito nos tratamentos, e também via pulverização, com solução de ureia. Foi utilizado o mesmo pulverizador empregado na aplicação do adubo nitrogenado na semeadura, inclusive com as mesmas regulagens de pressão e velocidade de aplicação. A distância entre os bicos de aplicação passou a ser de $0,75 \mathrm{~m}$.

As avaliações referentes à morfologia da planta foram realizadas aos 20, 40, 60, 80 e 100 dias após a emergência das plântulas (DAE). Para massa de matéria seca de plantas e área foliar fotossinteticamente ativa, foram coletadas cinco plantas a cada avaliação, o que corresponde a $0,85 \mathrm{~m}^{2}$ de área amostrada. Na determinação da massa da matéria seca, as plantas de milho foram cortadas rente ao solo. A biomassa coletada foi separada em folhas fotossinteticamente ativas do restante da planta. A seguir, o material vegetal foi picado, subamostrado e seco em estufa com aeração forçada a $65^{\circ} \mathrm{C}$ até atingir massa constante. Antes da secagem, as folhas passaram pelo integrador de área foliar, modelo LI 3100 da LI-COR, para determinação da área 
foliar fotossinteticamente ativa. A determinação da altura média da planta em centímetros foi realizada com régua e compreendeu a distância entre a região da superfície do solo e a inserção da folha +1 , aos 20, 40 e 60 DAE. Simultaneamente, foi determinado o diâmetro de colmo em centímetros, aos 20, 40, 60, 80 e 100 DAE. Considerou-se o diâmetro do segundo internódio, a partir do colo da planta, com uso de paquímetro.

Aos 115 DAE, quando o ponto de colheita foi atingido, os grãos com $23 \%$ de água foram colhidos e, para a amostragem, foram utilizadas 10 espigas de plantas presentes na área útil da parcela para determinações de matéria seca, comprimento, diâmetro, número de fileiras da espiga, massa de 1.000 grãos e produtividade. Para determinação da massa da matéria seca das espigas, a amostra foi triturada e, a seguir, foi subamostrada e seca em estufa com aeração forçada a $65^{\circ} \mathrm{C}$ até atingir massa constante. $\mathrm{O}$ comprimento médio em centímetros de espiga foi determinado através de medidas da base até o ápice da espiga, com auxílio da régua. $\mathrm{O}$ diâmetro médio em centímetros de espiga foi obtido no ponto correspondente ao centro da espiga, com o uso de paquímetro. O número médio de fileiras de grãos da espiga foi determinado, considerando-se as mesmas espigas utilizadas nas determinações do comprimento e os diâmetros médios de espiga e de sabugo.

A massa de 1.000 grãos foi determinada utilizando-se oito amostras de 100 sementes por tratamento. A produtividade de grãos foi obtida a partir da debulha e da pesagem dos grãos oriundos de espigas colhidas de 20 plantas contíguas na área útil das parcelas. Para determinação do teor de água, foi utilizado o método da estufa a $105^{\circ} \mathrm{C} \pm 3$ ${ }^{\circ} \mathrm{C}$ durante $24 \mathrm{~h}$ com base nas Regras para Análise de Sementes, sendo os dados extrapolados para área de um hectare e corrigidos para $13 \%$ de teor de água.

\section{Resultados e Discussão}

Em todas as avaliações realizadas, não houve efeitos decorrentes da aplicação do inoculante com Azospirillum brasilense nas sementes de milho e interação inoculante x doses de nitrogênio, apenas efeito isolado de doses de nitrogênio foi constatado pela análise estatística.

Os fatores que interferem nas respostas das culturas à inoculação de Azospirillum ainda não estão totalmente esclarecidos. Os resultados de sucesso encontrados na literatura da associação planta - Azospirillum estão relacionados, na maioria das vezes, a fatores da própria bactéria, como a escolha da estirpe, o número ideal de células por sementes e sua viabilidade (Mehnaz \& Lazarovits, 2006). Arsac et al. (1990) comentaram que a concentração da bactéria na solução do inoculante é mais importante que a dose. Para os autores, a concentração bacteriana ótima que promove o crescimento de plantas de milho é de 10 milhões de células viáveis $\mathrm{ml}^{-1}$, ou seja, aproximadamente 17 mil unidades formadoras de colônia semente ${ }^{-1}$. Níveis acima do ótimo apresentam efeito inibitório do crescimento das plantas inoculadas, enquanto concentrações baixas simplesmente não têm efeito algum na fase vegetativa.

Porém, o produto comercial utilizado neste estudo contém estirpes da bactéria Azospirillum brasilense em concentração mínima de 200 milhões de células viáveis $\mathrm{ml}^{-1}$, conforme preconizado pela legislação brasileira (Hungria, 2011). Considerando a dose utilizada neste experimento de $100 \mathrm{ml} \mathrm{ha}^{-1}$, 
a concentração bacteriana teórica foi de aproximadamente 340 mil unidades formadoras de colônia semente $^{-1}$, bem superior, portanto, ao mencionado por Arsac et al. (1990). Neste caso, a ausência da resposta à inoculação pode estar relacionada ao excesso de unidades formadoras de colônia.

Outro fator seria a diminuição na proporção de diazotróficos no solo em virtude da adição do fertilizante nitrogenado. A adição de fertilizante nitrogenado altera a diversidade destas bactérias (Bergamaschi, 2006). Hungria (2011), em trabalho com plantas de milho inoculadas, salienta que, nos tratamentos que receberam $100 \%$ de $\mathrm{N}$ na forma mineral de ureia, o efeito da inoculação com Azospirillum foi em geral anulado.

Quanto ao efeito isolado das doses de $\mathrm{N}$ na morfologia das plantas de milho, em todas as épocas de avaliação, foram observados efeitos quadráticos nas massas de matéria seca da folha (MMSF) e matéria seca do colmo (MMSC), com elevação das doses de nitrogênio (Figura 2A e B).

Os resultados obtidos corroboram com outros publicados, em que as respostas positivas são relacionadas ao acúmulo de massa de matéria seca pelas plantas em função da aplicação de doses de $\mathrm{N}$ (Araújo et al.,2004; Gomes et al., 2007).

Este e outros estudos disponíveis na literatura evidenciam a estreita relação do crescimento das plantas de milho com o suprimento de N. O processo de crescimento do vegetal depende do $\mathrm{N}$ para realização da síntese de proteína, absorção iônica, fotossíntese, respiração, multiplicação e diferenciação celular, proporcionando uma vegetação verde e abundante, com aumento da folhagem e rápido crescimento (Okumura et al., 2011).

Para a área foliar fotossinteticamente ativa, foram observados efeitos quadráticos em todas as épocas de avaliação para doses de $\mathrm{N}$ superiores a $105 \mathrm{~kg} \mathrm{ha}^{-1}$ (Figura 2C). Os maiores valores de área foliar foram registrados aos $60 \mathrm{DAE}$ (florescimento), diminuindo a partir dessa fase, independente do tratamento.

$\mathrm{O}$ aumento do teor de $\mathrm{N}$ disponibilizado às plantas proporcionou maior crescimento e aumento da área foliar. Folhas bem nutridas em $\mathrm{N}$ têm maior capacidade de assimilar $\mathrm{CO}_{2}$ e sintetizar carboidratos durante a fotossíntese, resultando em maior crescimento e duração da área foliar. $\mathrm{Na}$ fase de grão leitoso, a planta necessita apresentar teores de sólidos solúveis prontamente disponíveis, objetivando a evolução do processo de formação de grãos. Assim, a fotossíntese mostra-se imprescindível. Em termos gerais, considera-se como importante característica condicionadora de produção a extensão da área foliar, que permanece fisiologicamente ativa após a emergência das espigas (Castro et al., 2008).

A deficiência de $\mathrm{N}$ pode acelerar a senescência foliar devido ao retranslocamento de nitrogênio das folhas mais velhas para os pontos de crescimento, diminuindo a área foliar fotossinteticamente ativa. Esse processo promove significativa queda no rendimento da cultura, principalmente pela redução do comprimento e do diâmetro das espigas, peso de espigas e de grãos (Wolschick et al., 2003).

A altura das plantas foi influenciada pelas doses de $\mathrm{N}$ nas três épocas avaliadas. Aos 20 dias após a emergência (DAE), o efeito foi linear, acompanhando o aumento da dose de N. Nas demais épocas, foram observados efeitos quadráticos. A partir dos 40 DAE, o crescimento em altura continuou sendo maior para as plantas adubadas com N. No entanto, aumentos da dose de $\mathrm{N}$ não resultaram em maior altura de planta aos 60 DAE (Figura 2D). 


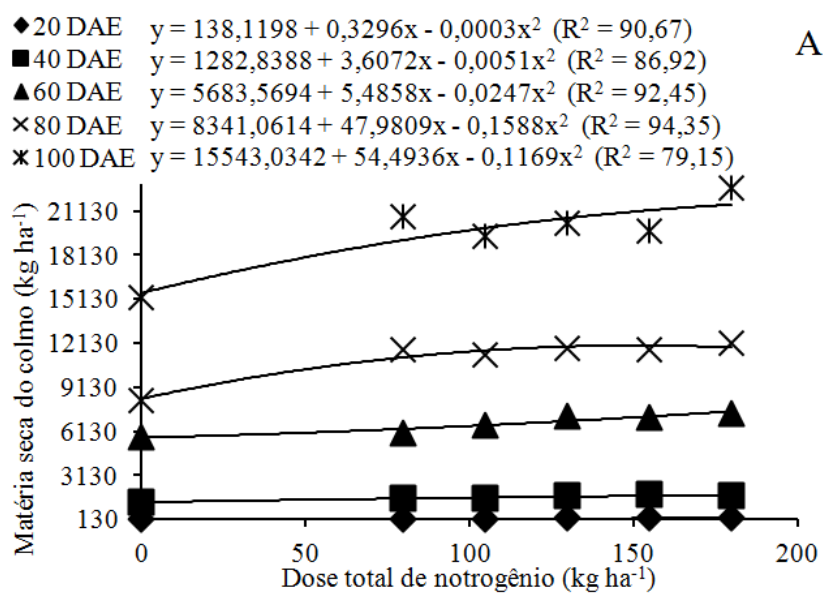
A
-20 DAE $\mathrm{y}=133,9843+0,2441 \mathrm{x}-0,0007 \mathrm{x}^{2}\left(\mathrm{R}^{2}=89,82\right)$
-40 DAE $\mathrm{y}=1008,6869+3,9714 \mathrm{x}-0,0117 \mathrm{x}^{2}\left(\mathrm{R}^{2}=95,74\right)$
\60 DAE $\mathrm{y}=2166,3066+6,2654 \mathrm{x}-0,0116 \mathrm{x}^{2}\left(\mathrm{R}^{2}=98,02\right)$
$\times 80 \mathrm{DAE} \quad \mathrm{y}=1130,4219+5,2770 \mathrm{x}-0,0013 \mathrm{x}^{2}\left(\mathrm{R}^{2}=91,51\right)$
* 100 DAE $y=529,3126+3,3459 x-0,0102 x^{2}\left(R^{2}=94,33\right)$

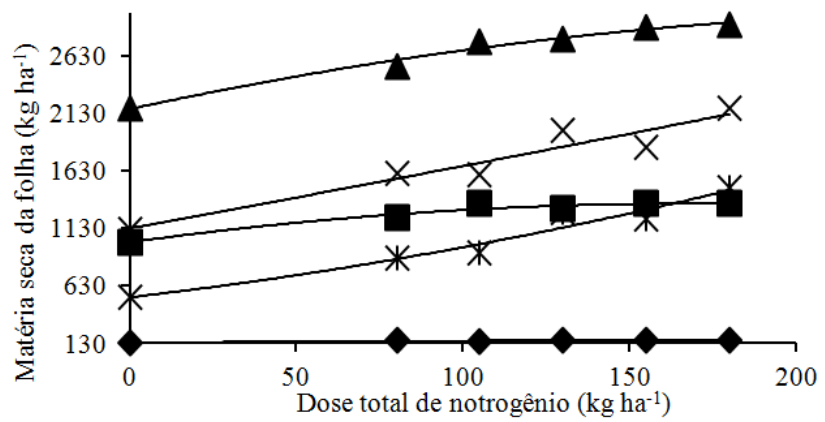

-20 DAE $\mathrm{y}=7,7611+0,0228 \mathrm{x}-0,0001 \mathrm{x}^{2}\left(\mathrm{R}^{2}=93,61\right)$

- $40 \mathrm{DAE} \mathrm{y}=66,4334+0,2834 \mathrm{x}-0,0012 \mathrm{x}^{2}\left(\mathrm{R}^{2}=77,61\right)$

C

-20 DAE $\mathrm{y}=15,182+0,0143 \mathrm{x}\left(\mathrm{R}^{2}=86,78\right)$

- 40 DAE $y=-0,0009 x^{2}+0,2646 x+65,732\left(R^{2}=99,14\right)$

$\triangle 60 \mathrm{DAE} \quad \mathrm{y}=148,0737+0,2942 \mathrm{x}-0,0002 \mathrm{x}^{2}\left(\mathrm{R}^{2}=97,23\right)$

$\times 80 \mathrm{DAE} \quad \mathrm{y}=138,2195+0,4682 \mathrm{x}-0,0015 \mathrm{x}^{2}\left(\mathrm{R}^{2}=92,00\right)$

* 100 DAE $y=76,6001+0,03909 x-0,0012 x^{2}\left(R^{2}=96,55\right)$

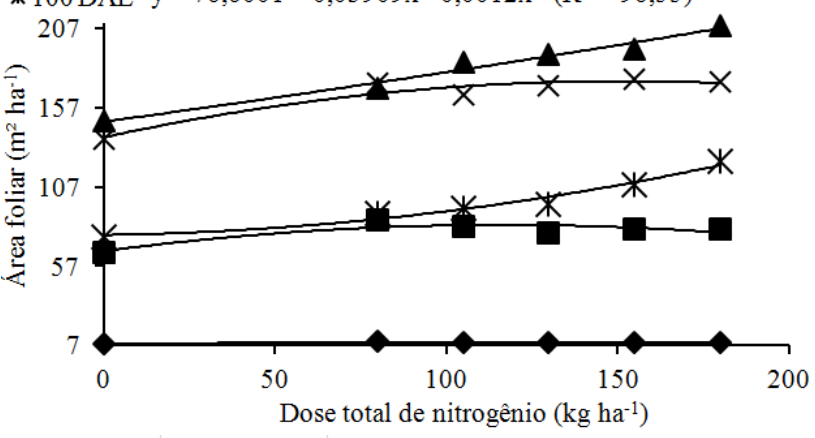

$\Delta 60 \mathrm{DAE} \mathrm{y}=190,036+0,2408 \mathrm{x}-0,0006 \mathrm{x}^{2}\left(\mathrm{R}^{2}=97,79\right)$

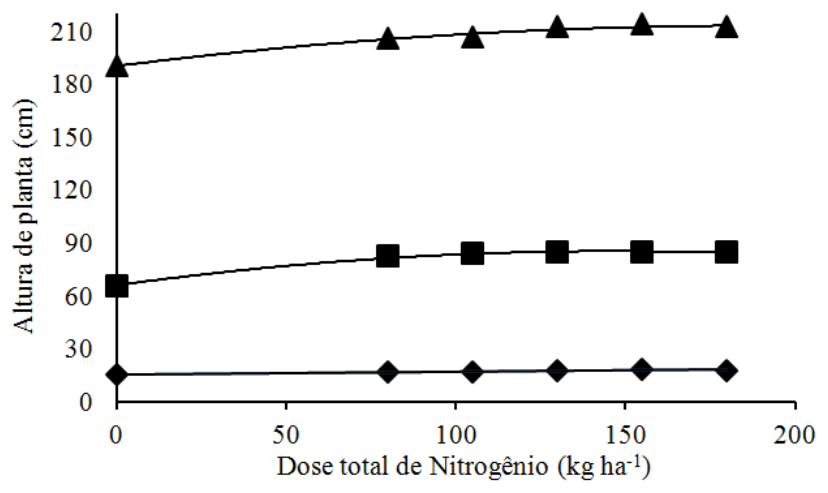

-20 DAE y=1,4725+0,0031x-0,0009x $x^{2}\left(R^{2}=94,55\right)$

- 40 DAE $y=1,7856+0,0016 \mathrm{x}-0,0000 \mathrm{x}^{2}\left(\mathrm{R}^{2}=77,77\right)$

$\mathrm{E}$

$y=162,3878+0,3013 x-0,0003 x^{2}\left(R^{2}=96,28\right)$

F

$\triangle 60 \mathrm{DAE} \quad \mathrm{y}=2,1341+0,0027 \mathrm{x}-0,0000 \mathrm{x}^{2}\left(\mathrm{R}^{2}=86,78\right)$

$\times 80 \mathrm{DAE} \quad \mathrm{y}=1,8055+0,0016 \mathrm{x}-0,0000 \mathrm{x}^{2}\left(\mathrm{R}^{2}=91,01\right)$

* 100 DAE $y=1,7083+0,0038 x-0,0009 x^{2}\left(R^{2}=98,40\right)$
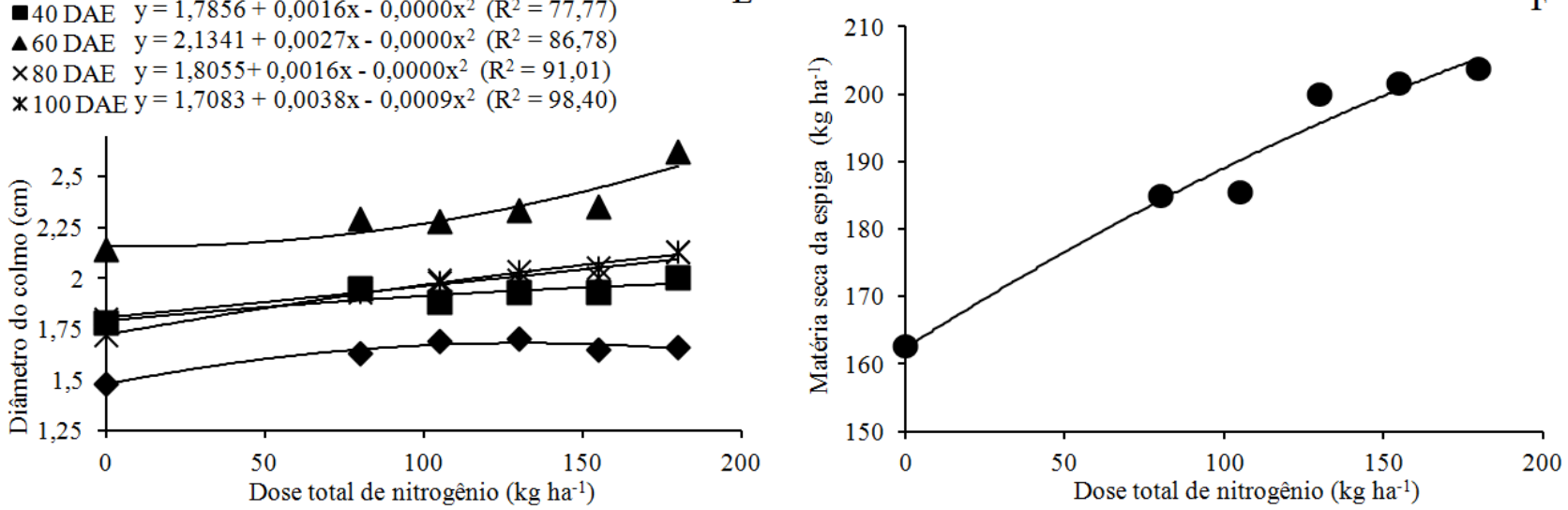

FIGURA 2. Análise de regressão para matéria seca da folha (A), matéria seca do colmo (B), área foliar (C), altura de planta (D), diâmetro de colmo (E) e matéria seca da espiga (F) de planta de milho submetida a seis doses de nitrogênio, zero, 80, 105, 130, 155, $180 \mathrm{~kg} \mathrm{ha}^{-1}$ em cinco épocas de avaliação: 20, 40, 60, 80 e 100 dias após a emergência das plântulas (DAE). 
TABELA 3. Correlações simples de Pearson para produtividade versus componentes da espiga, matéria seca da espiga (M.S.E), diâmetro do sabugo ( $\varnothing$ sabugo), diâmetro da espiga ( $\varnothing$ espiga), comprimento da espiga (C.E.), número de fileiras de grãos (N.F.), massa de 1.000 grãos (M.M.S) e produtividade na colheita.

Componentes da espiga

\begin{tabular}{|c|c|c|c|c|c|c|c|}
\hline \multirow[t]{2}{*}{ Produtividade } & \multirow[t]{2}{*}{$X$} & M.S.E. & $\varnothing$ sabugo & $\varnothing$ espiga & C.E. & N.F. & M.M.S. \\
\hline & & $0,930^{* *}$ & $0,679^{* *}$ & $0,818^{* *}$ & $0,779^{* *}$ & $0,212^{\mathrm{ns}}$ & $0,930^{* *}$ \\
\hline
\end{tabular}

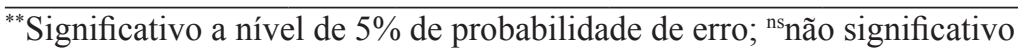

A altura de planta é influenciada pela disponibilidade de nitrogênio no solo, uma vez que este nutriente participa diretamente da divisão e expansão celular e do processo fotossintético, sendo o efeito do aumento da dose de $\mathrm{N}$ na altura de plantas de milho visível somente até determinada fase de crescimento, pois, com o paulatino autossombreamento das plantas, assim como o sombreamento mútuo entre elas, ocorre redução do crescimento até que a altura máxima seja atingida quando do florescimento (Castro et al., 2008).

No estudo de Wolschick et al. (2003), a partir dos 44 DAE até o final do estádio vegetativo das plantas, não foram observadas diferenças na altura das plantas entre os tratamentos que receberam adubação nitrogenada e somente as plantas do tratamento sem $\mathrm{N}$ apresentaram altura das plantas estatisticamente inferiores.

Para doses de $\mathrm{N}$ superiores a $80 \mathrm{~kg} \mathrm{ha}^{-1}$, o efeito sobre o diâmetro do colmo foi pouco significativo, em todas as épocas de avaliação, sendo este efeito melhor representado por equações quadráticas (Figura 2E).

A partir dos 60 dias após a emergência, começou a redução nos valores do diâmetro do colmo, provavelmente devido à remobilização das reservas nele contidas, para sustentar de maneira adequada o estádio de florescimento e desenvolvimento da espiga. A capacidade produtiva da planta está também relacionada com sua capacidade em acumular e transferir carboidratos do colmo para a formação e o enchimento de grãos (Castro et al., 2008).

$\mathrm{O}$ aumento da massa da matéria seca das espigas, com o aumento da disponibilidade de $\mathrm{N}$ (Figura 2F), foi diretamente influenciado pelos aumentos nos componentes de produção, como a massa de 1.000 grãos (Figura 3C).

A deficiência de nutrientes aos 20, 40, 60, 80 e 100 dias após a emergência das plântulas pode reduzir severamente o tamanho das espigas a serem colhidas (Figura 3A). Quando não limitada por outros fatores, a maior disponibilidade de $\mathrm{N}$ aumenta o potencial da planta em definir maiores número e massa de sementes por espiga, aumentando, desse modo, sua massa total (Pöttker \& Wiethölter, 2004).

Todos os componentes da espiga avaliados respondem significativamente às doses de $\mathrm{N}$ aplicadas, exceto o número de fileiras (Figura 3A, B, C e D).

O número de fileiras de grãos é definido no estádio V8, fase em que há disponibilidade de nutrientes, especialmente $\mathrm{N}$, uma vez que nesta época é iniciada elevação da demanda desse nutriente pela planta. A não alteração do número de fileiras 

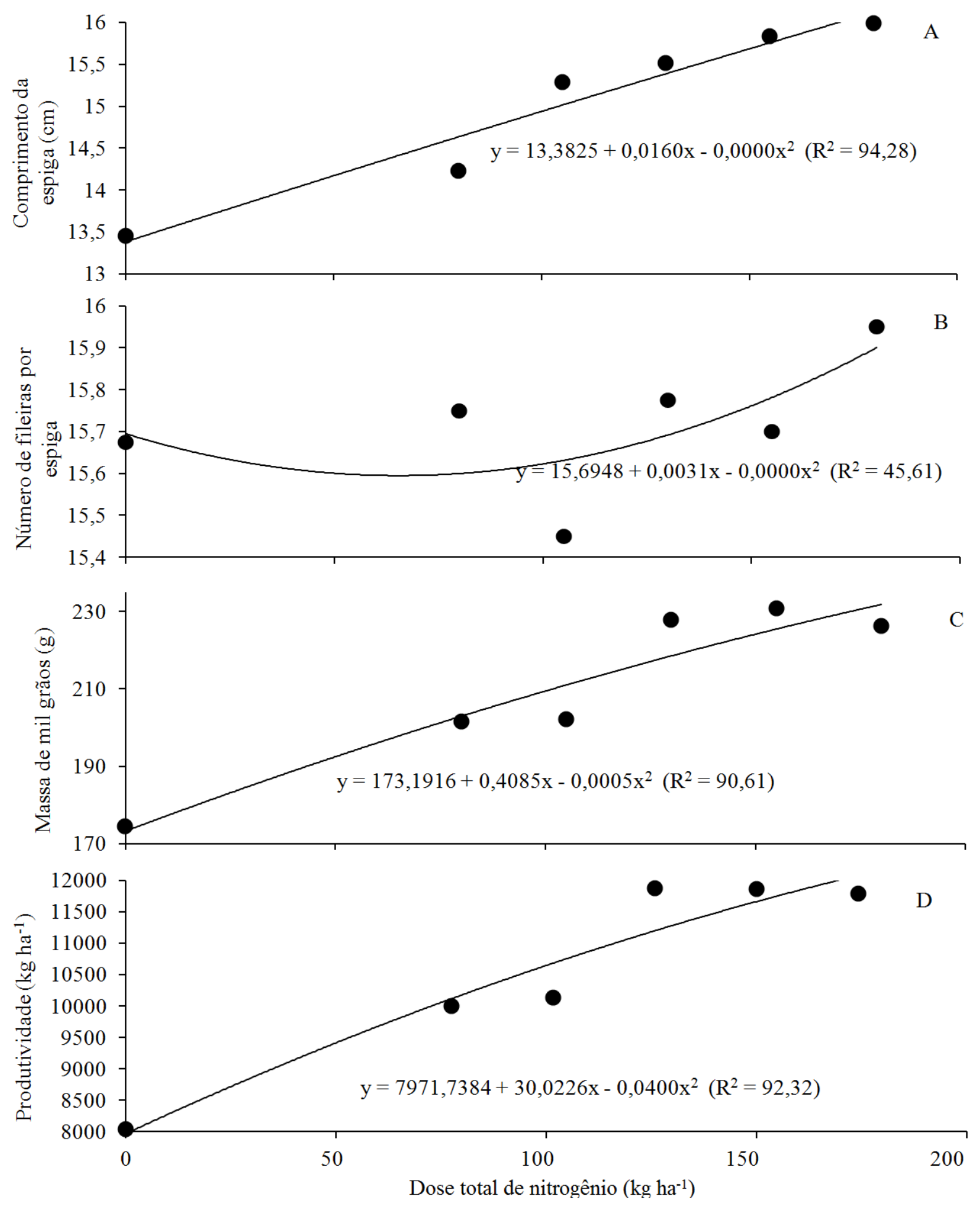

FIGURA 3. Análise de regressão do comprimento de espiga (A), número de fileira (B), massa de 1.000 grãos (E) e produtividade de grãos na colheita (D) submetida a seis doses de nitrogênio: zero, 80, 105, 130, 155, 180 $\mathrm{kg} \mathrm{ha}^{-1}$. 
observada discorda dos resultados apresentados por Carmo et al. (2012), que obtiveram aumento linear significativo dessa característica, em resposta ao aumento das doses de N. Por outro lado, Tomazela (2005) não verificou efeito de doses crescentes de $\mathrm{N}$ no número de fileiras de grãos por espiga. Segundo este autor, a ausência ou a existência de registro de efeito na literatura pode ser explicada pelas diferentes condições de solo e de ambiente nas diferentes áreas experimentais, além da grande variabilidade entre os híbridos disponíveis atualmente, quanto à característica estudada.

A deficiência de nutrientes aos 20, 40, 60, 80 e 100 dias após a emergência das plântulas pode reduzir o tamanho das espigas a serem colhidas (Figura 3). Quando não limitada por outros fatores, a maior disponibilidade de $\mathrm{N}$ aumenta o potencial da planta em definir maiores número e massa de sementes por espiga (Pöttker \& Wiethölter, 2004).

Nas figuras 3C e D, estão apresentadas as equações de regressão das características da espiga, como massa de 1.000 grãos, e da produtividade de plantas de milho, como consequência das doses de $\mathrm{N}$ aplicadas.

Para a massa de 1.000 grãos e a produtividade de grãos, as respostas à adubação nitrogenada na literatura são variadas. Oliveira \& Caires (2003) verificaram aumento linear da massa de 1.000 sementes em função do aumento das doses de $\mathrm{N}$ e que tal componente de produção foi decisivo para aumentar a produtividade de grãos. No entanto, Casagrande \& Fornasieri Filho (2002) não constataram efeito de doses e de épocas de aplicação de N na massa de 1.000 sementes.

Segundo Cruz et al. (2008), os componentes da espiga, além de influenciarem na massa da matéria seca das espigas, influem de forma substancial na produtividade de grãos. Essa correlação foi observada no presente estudo (Tabela 3). Com exceção do número de fileiras por espiga, todos os demais componentes avaliados apresentaram correlação positiva com a produtividade. A massa de 1.000 grãos (M.M.S) e a massa seca da espiga (M.M.E) foram os componentes que tiveram a maior correlação $(0,930)$, seguidas do diâmetro da espiga $(0,818)$.

Outras pesquisas, avaliando produtividade de milho com diferentes doses de N, resultaram em produtividades de grãos aumentadas conforme foram elevadas as doses de N. No ensaio de Araújo et al. (2004), a dose de $240 \mathrm{~kg} \mathrm{ha}^{-1}$ de $\mathrm{N}$ proporcionou um aumento de $28 \%$ na produtividade de grãos quando comparada ao tratamento testemunha, que recebeu a dose zero $\mathrm{kg} \mathrm{ha}^{-1}$ de N. Amaral Filho et al. (2005) verificaram que o aumento nas doses de nitrogênio de zero $\mathrm{kg} \mathrm{ha}^{-1}$ para $150 \mathrm{~kg} \mathrm{ha}^{-1}$ proporcionou maior massa de 1.000 grãos e com efeitos positivos na produtividade de grãos.

\section{Conclusões}

A aplicação da bactéria diazotrofica Azospirillum brasilense via solução nas sementes, acompanhada ou não de doses de nitrogênio sintético, não interfere no desenvolvimento de plantas e na produtividade da cultura do milho.

A adoção desta prática não substitui o uso de fertilizantes nitrogenados e tampouco permite a redução da dose.

A adição de fertilizantes nitrogenados promove maior desenvolvimento das plantas, com aumento da produtividade. 


\section{Referências}

AMARAL FILHO, J. P. R.; FORNASIERI FILHO, D.; FARINELLI, R.; BARBOSA, J. C. Espaçamento, densidade populacional e adubação nitrogenada na cultura do milho. Revista Brasileira de Ciência do Solo, Viçosa, MG, v. 29, n. 3, p. 467-473, 2005.

ARAÚJO, L. A. N.; FERREIRA, M. E.; CRUZ, M. C. P. Adubação nitrogenada na cultura do milho. Pesquisa Agropecuária Brasileira, Brasília, DF, v. 39, n. 8, p. 771-777, 2004.

ARSAC, J. F.; LAMOTHE, C.; MULARD, D.; J. FAGES, J. Growth enhancement of maize (Zea mays L.) through Azospirillum lipoferum inoculation: effect of plant genotype and bacterial concentration. Agronomie, Paris, v. 10, p. 640-654, 1990.

BARTCHECHEN, A.; FIORI, C. C. L.; WATANABE, S. H.; GUARIDO, R. C. Efeito da inoculação de Azospirillum brasilense na produtividade da cultura do milho (Zea mays L.) - Campo Digit@1, Campo Mourão, v. 5, n. 1, p. 56-59, 2010.

BERGAMASCHI, C. Ocorrência de bactérias diazotróficas associadas às raízes e colmos de cultivares de sorgo. 2006. Dissertação (Mestrado em Microbiologia Agrícola) Universidade Federal do Rio Grande do Sul, Porto Alegre.

CANTARELLA, H. Nitrogênio. In: NOVAIS, R. F.; ALVAREZ V., V. H.; BARROS, N. F.; FONTES, R. L. F.; CANTARUTTI, R. B.; NEVES, J. C. L. (Ed.). Fertilidade do solo. Viçosa, MG, Sociedade Brasileira de Ciência do Solo, 2007. p. 375-470.

CASAGRANDE, J. R. R.; FORNASIERI FILHO,
D. Adubação nitrogenada na cultura do milho safrinha. Pesquisa Agropecuária Brasileira, Brasília, DF, v. 37, n. 1, p. 33-40, 2002.

CASTRO, P. R. C.; KLUGE, R. A.; SESTARI, I. Manual de fisiologia vegetal: fisiologia de cultivos. São Paulo: Agronômica Ceres, 2008. 864 p.

CARMO, M. S.; CRUZ, S. C. S.; SOUZA, E. J.; CAMPOS, L. F. C.; MACHADO, C. G. Doses e fontes de nitrogênio no desenvolvimento e produtividade da cultura de milho doce (Zea mays convar. saccharata var. rugosa). Bioscience Journal, Uberlândia, v. 28, p. 223-231, 2012. Suplemento, 1.

CRUZ, S. C. S.; PEREIRA, F. R. S.; SANTOS, J. R.; ALBUQUERQUE, A. W.; PEREIRA R. G. Adubação nitrogenada para o milho cultivado em sistema plantio direto, no Estado de Alagoas. Revista Brasileira de Engenharia Agrícola e Ambiental, Campina Grande, v. 12, n. 1, p. 62-68, 2008. ELMERICH. C.; NEWTON, W. E. Associative and eudoplrytic nitrogen-fíxing bactéria and cyauobacterial associatious. Dordrecht: Springer, 2007. 321 p. (Nitrogen Fixation: Origins, Applications, and Research Progress, v. 5).

GOMES. R. F.; SILVA, A. G. da; ASSIS. R. X. de; PIRES. F. R. Efeito de doses e da época de aplicação de nitrogênio nos caracteres agronômicos da cultura do milho sobre plantio direto. Revista Brasileira de Ciência do Solo, Viçosa, MG, v. 31. n. 5. p. 931-938, 2007.

HARTMANN, A.; BALDAM, J. I. The genus Azospirillum. In: DWORKIN, M.; FALKOW, 
S.; ROSENBERG, E.; SCHLEIFER, K. H.; STACKEBRANDT, E. (Ed.). The Prokaryotes. New York: Springer, 2006. p.115-140.

HUNGRIA, M. Inoculação com Azospirillum brasilense: inovação em rendimento a baixo custo. Londrina: Embrapa Soja, 2011. 38 p. (Embrapa Soja. Documentos, 325).

MEHNAZ, S.; LAZAROVITS, G. Inoculation effects of Pseudomonasputida. Ghiconacetobacter azotocaptans. and Azospirillum lipoferum on com plant growth iinder greenhouse conditions. Mícrobial Ecology. New York. v. 51, n. 3, p. 326-335, 2006.

OLIVEIRA, J. M. S.; CAIRES, E. F. Adubação nitrogenada em cobertura para o milho cultivado após aveia preta no sistema plantio direto. Acta Scientiarum Agronomy, Maringa, v. 25, p. 351-357, 2003.

OKUMURA R. S.; MARIANO, D. C.; ZACCHEO, P. V. C. Uso de fertilizante nitrogenado na cultura do milho: uma revisão. Pesquisa Aplicada \& Agrotecnologia, Guarapuava, v. 4, n. 2, p. 26-244, 2011.

PÖTTKER, D.; WIETHÖLTER, S. Épocas e métodos de aplicação de nitrogênio em milho cultivado no sistema plantio direto. Ciência Rural, Santa Maria, v. 34, n. 4, p. 1015-1020, 2004.

RAIJ, B. van; ANDRADE, J. C.; CANTARELLA, H.; QUAGGIO, J. A. Análise química para avaliação da fertilidade de solos tropicais. Campinas: Instituto Agronômico, 2001. 284 p.
SAIKIA, S. P.; JAIN, V. Biological nitrogen fixation with non-legumes: an achievable Target or a dogma? Current Science. Bangalore. v. 92, n. 3, p. 317-322, 2007.

SISTEMA Brasileiro de Classificação de Solos. Brasília, DF: Embrapa Produção de Informação; Rio de Janeiro: Embrapa Solos, 1999. $412 \mathrm{p}$.

SUBEDI, K. D.; MA, B. L. Assessment of some major yield-limiting factors on maize production in a humid temperate environment. Field Crops Research, Amsterdam, v. 110, n. 1, p. 21-26, 2009.

TOMAZELA, A. L. Adubação nitrogenada e de micronutrientes na produtividade $e$ incidência de doenças foliares em milho. 2005. 58 f. Dissertação (Mestrado) - Escola Superior de Agricultura Luiz de Queiroz, Universidade de São Paulo, Piracicaba.

USDA. UNITED STATES DEPARTMENT OF AGRICULTURE. World corn production, consumption. and stocks. 2011. Disponível em: <http://www.fasAisda.gov/psdonliue/ psdRepoi1.aspx7hidRepoilRetriCom+Pro duction $\% 2 \mathrm{c}+$ Conswiiption $\% \&$ hidReportR etiievalI $=59 \&$ evalTemplateID $=7>$. Acesso em: 9 nov. 2012.

WOLSCHICK, D.; CARLESSO, R.; PETRY, M. T; JADOSKI, S. O. Adubação nitrogenada na cultura do milho no sistema plantio direto em ano com precipitação pluvial normal e com "El Niño". Revista Brasileira de Ciência do Solo, Campinas, v. 27, p. 461-468, 2003. 